\title{
Evidence based practice in postgraduate healthcare education: A systematic review Gemma Flores-Mateo ${ }^{1,2}$ and Josep M Argimon*2
}

Address: ${ }^{1}$ Unitat d'Epidemiologia, Salut Pública i Serveis Sanitaris, IDIAPJordi Gol, Barcelona, Spain and 2Divisio d'avaluació, Servei Catala de la Salut, Barcelona, Spain

Email: Gemma Flores-Mateo - gflores@fundaciojgol.org; Josep M Argimon* - jargimon@catsalut.net

* Corresponding author

Published: 26 July 2007

BMC Health Services Research 2007, 7:119 doi:10.1186/1472-6963-7-119

This article is available from: http://www.biomedcentral.com//472-6963/7/II 9

(C) 2007 Flores-Mateo and Argimon; licensee BioMed Central Ltd.

This is an Open Access article distributed under the terms of the Creative Commons Attribution License (http://creativecommons.org/licenses/by/2.0), which permits unrestricted use, distribution, and reproduction in any medium, provided the original work is properly cited.
Received: 27 February 2007

Accepted: 26 July 2007

\begin{abstract}
Background: Training in Evidence-Based Practice (EBP) has been widely implemented throughout medical school and residency curricula. The aim of this study is to systematically review studies that assessed the effectiveness of EBP teaching to improve knowledge, skills, attitudes and behavior of postgraduate healthcare workers, and to describe instruments available to evaluate EBP teaching.

Methods: The design is a systematic review of randomized, non-randomized, and before-after studies. The data sources were MEDLINE, Cochrane Library, EMBASE, CINAHL and ERIC between 1966 and 2006. Main outcomes were knowledge, skills, attitudes and behavior towards EBP. Standardized effect sizes (E-S) were calculated. The E-S was categorized as small $(E-S<0.2)$, small to moderate (E-S between 0.2 and 0.5 ), moderate to large (E-S between $0.5 \mathrm{I}$ and 0.79 ), large (E-S $>0.79$ ). Reliability and validity of instruments for evaluating education were assessed. Studies excluded were those that were not original, performed in medical students, focused on prescribing practices, specific health problems, theoretical reviews of different components of EBP, continuing medical education, and testing the effectiveness of implementing guidelines.
\end{abstract}

Results: Twenty-four studies met our inclusion criteria. There were 15 outcomes within the 10 studies for which E-S could be calculated. The E-S ranged from 0.27 ( $95 \% \mathrm{Cl}:-0.05$ to 0.59$)$ to 1.32 (95\%Cl: I.I I to I.53). Studies assessing skills, behavior and/or attitudes had a "small to moderate" E-S. Only I of the 2 studies assessing knowledge had E-S of 0.57 ( $95 \mathrm{Cl}: 0.32$ to 0.82 ) and 2 of the 4 studies that assessed total test score outcomes had "large" E-S. There were 22 instruments used, but only 10 had 2 or more types of validity or reliability evidence.

Conclusion: Small improvements in knowledge, skills, attitudes or behavior are noted when measured alone. A large improvement in skills and knowledge in EBP is noted when measured together in a total test score. Very few studies used validated measures tests.

\section{Background}

One of the most consistent findings in health-service research is the gap between best practice (as determined by scientific evidence) on the one hand and actual clinical care on the other $[1,2]$. Over the past decade, evidencebased clinical guidelines have become a major feature of healthcare provision. Biomedical researchers in many countries have established programs to garner evidence in 
the diagnosis and treatment of health problems, and to disseminate these guidelines in order to improve the quality of care provision. However, several studies have suggested that clinical use of these guidelines does not occur, that between 10 and $40 \%$ of patients do not receive care based on current scientific evidence, and that $\geq 20 \%$ of care provided is not needed or is potentially harmful to the patients $[1,3-5]$.

A strategy to reduce these deficits in care provision is to increase the number of Evidence Based Practice (EBP) training programs [6-8]; their goal being to improve outcomes for patients by increasing postgraduate health care knowledge, skills and attitudes towards EBP [9]. However, published reports on effectiveness of these training schemes have shown conflicting results [10-13].

A crucial aspect in evaluating education programs is the choice of instrument for evaluating the effect of the educational training [14]. The rigor with which investigators and educators construct and/or administer the instrument could affect the reliability, validity and feasibility of the evaluation $[14,15]$. As such, a systematic and comprehensive review of existing instruments is necessary so as to describe the relationships between different educational instruments and the effectiveness of an EBP course in increasing knowledge, skills, attitudes and behavior in EBP and, as such, to be able to select the instrument that best assesses effectiveness of EBP training.

Hence, the purpose of this present study was to perform a systematic review of the studies that had assessed the effectiveness of teaching EBP whose objectives were to improve knowledge, critical appraisal skills, attitudes and behavior of postgraduate healthcare workers. We examined, as well, the measures used to evaluate the effectiveness of the intervention, together with their reliability and validity.

\section{Methods}

\section{Search strategy and study selection}

We searched: (1) MEDLINE, (2) Cocharane Library, (3) EMBASE, (4) the Cumulative Index of Nursing and Allied Health Literature (CINAHL ${ }^{\circledast}$ ) and ERIC. We designed a search strategy for MEDLINE, accessed via PubMed, for studies investigating the effectiveness of EBP training in clinical practice by using free text and the Medical Subject Headings (MeSH) terms evidence based medicine, evidence based health care, evidence based practice, critical appraisal, knowledge, attitude, skills, behavior, clinical competence, teach, education intervention, courses, journal club, workshops, multifaceted intervention, residents, physicians, nurses, health care professionals, postgraduates. The literature search period covered January 1966 through December 2006, with no language restrictions.
Also, we reviewed the reference lists of the relevant original papers and reviews.

We aimed to identify all the randomized, non-randomized and before-and-after comparison studies that assessed the effectiveness of teaching EBP designed to improve knowledge, skills, attitudes and behavior in postgraduate healthcare workers. Our exclusion criteria were studies that focused on (a) prescribing; (b) specific health problems; (c) theoretical reviews of different components of EBP (searching skills, formulating questions); (d) continuing medical education in general (not specifically in EBP); (e) undergraduates; ( $f$ ) testing the effectiveness of implementing guidelines; (g) evaluating teaching methods using IT devices (PDA or computer-based reminder); (h) no original studies; and (i) medical students. When several papers were published from the same population, the publication with the longest follow-up was preferred.

\section{Data abstraction}

Two investigators (G.F-M., J.M.A) independently abstracted the articles that met the selection criteria. Discrepancies were resolved by consensus. We reviewed each article that met the selection criteria and abstracted the data by using standardized data abstraction forms. Data abstracted were author, year of publication, country, design, participants (discipline and level), sample size, outcome, EBP intervention, duration and frequency of intervention, instruments for evaluating education, feasibility, and the types of reliability and validity assessed.

Feasibility was defined as documentation of some measure of ease of implementation of the questionnaire; time required to administer instrumentation, time required to score instrumentation, and the costs involved in administration and scoring. Reliability is concerned with that portion of measurement that is due to permanent effects which persist from sample to sample. Two broad types of reliability were abstracted: test-retest score or temporal stability and internal consistency. Types of validity assessed were those based on: content, internal structure (internal consistency and dimensionality), and relationships with other variables (responsive and discriminative criteria).

We assigned the types of outcome to the following categories: knowledge of EBP, skills defined as the participant applying knowledge by performing EBP steps in some scenarios, attitudes towards EBP, behavior defined as actual performance of EBP in practice. When two or more outcomes were combined in a score, we described this as a total test score. 
We used the recommended questions for appraising reports of medical education interventions to assess study quality [14].

\section{Data synthesis}

For those outcomes in which it was possible, we calculated an effect-size (E-S) for each outcome category, and are measures of the magnitude of an intervention effect [16]. The E-S is the difference in means divided by the square root of the pooled-group variances. Unless common metric units were used, this provides different units for outcomes measured. Converting the effect of the different studies to E-S enables comparisons to be made between studies. E-S calculations were made using the effect size generator software program [17]. The E-S was defined as "small" (E-S < 0.2), "small to moderate" (E-S between 0.2 and 0.5 ), "moderate to large" (E-S between 0.51 and 0.79), "large" (E-S > 0.79). We could not use meta-analysis of E-S for several reasons: (a) because the heterogeneity and diversity of outcomes reported do not allow for a clear metric scale to be used across the studies; (b) important information necessary for pooling studies (such as variance estimates) was missing in many studies; and (c) the diversity of studies (including populations, interventions and follow-up time) was not amenable to pooling.

We assessed publication bias by using the Begg and the Egger tests test and funnel plots, which graphically display the magnitude of the effect estimated as the inverse of variance of the study. All statistical analyses were conducted by using Stata software version 9.0 (STATA Corp, College Station, TX) and with S-PLUS version 7 (Insightful Corporation, Seattle, WA).

\section{Results}

\section{Study characteristics}

We identified 481 published articles based on our search criteria. Following a review of the abstracts, we retrieved the full text of 29 and assessed them for information on effectiveness of EBP training in postgraduate healthcare workers. After applying the full review, 24 reports were finally included in the current evaluation (Figure 1).

The studies were published between 1988 and 2006 (see Additional file 1). There were 11 randomized controlled trials (RCT) [18-28], 5 non-randomized clinical trials (NRCT) [29-33] and 8 before-after studies [34-41]. Stud-

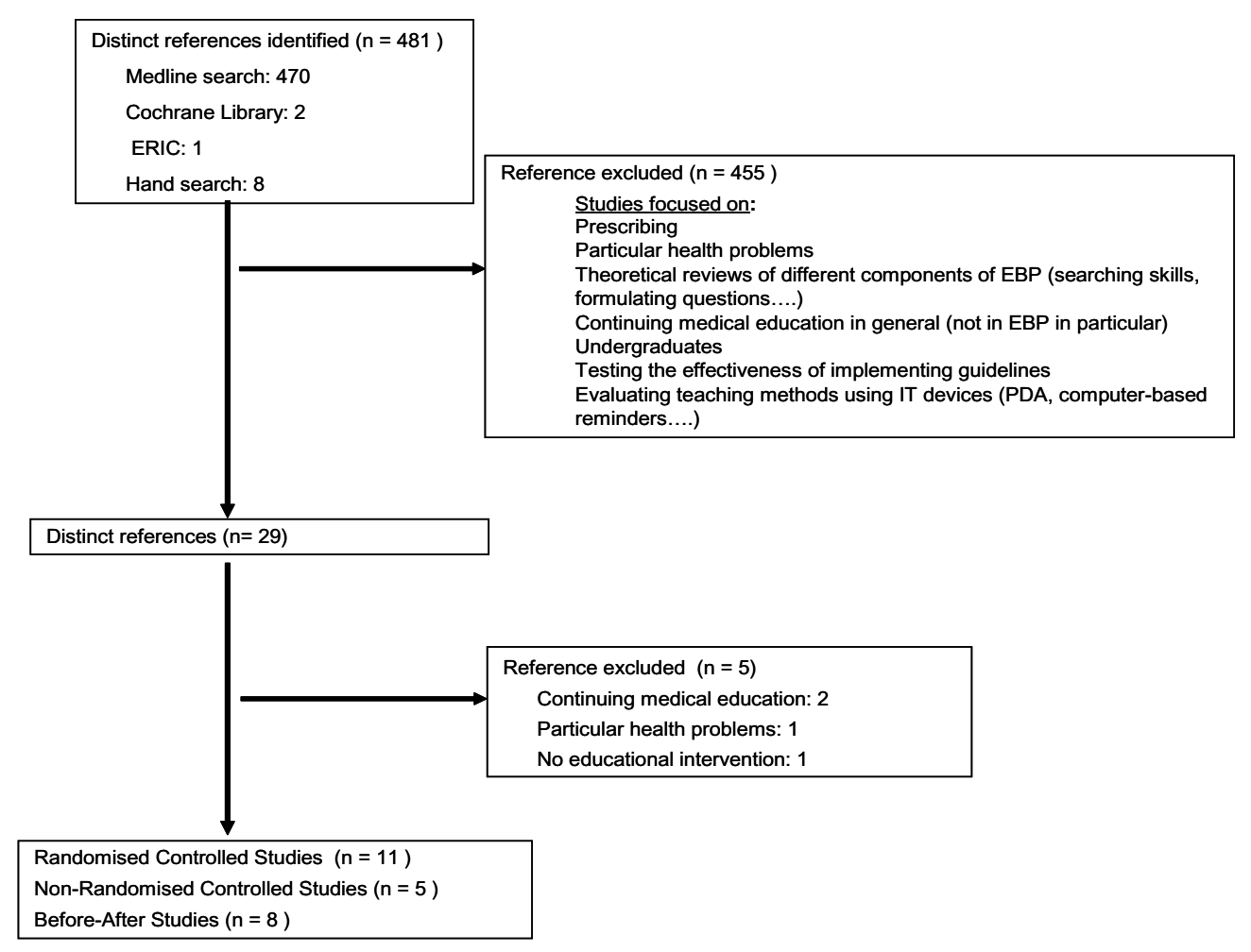

Figure I

Study selection process. 
ies were geographically heterogeneous, and sample sizes varied considerably (between 12 and 800 subjects). In most of the studies the population was residents in medicine. Teaching methods included workshops, multifaceted intervention, internet-based intervention or journal club. The journal club was the most common format $[18,21,30,31,35]$. The duration of the teaching schedules ranged from 15 minutes to several years.

Both the Begg and the Egger tests were significant ( $\mathrm{p}<$ 0.05 ) and the funnel plot did not suggest any publication or related bias (Figure 2).

\section{Characteristics of EBP evaluation instruments}

We found 22 instruments for evaluating education in EBP with two instruments being used in more than one study $[33,36,38,40]$. Feasibility of implementation was poorly reported for all instruments. None reported the time required for administering or scoring the instruments and none estimated the financial cost of implementation. Ten instruments $(45.4 \%)$ were validated with at least two or more types of evidence of validity or reliability. The responsive validity was the one most commonly tested (90.9\%) followed by discriminative $(27.3 \%)$ and content validity $(27.3 \%)$ (Table 1$)$

\section{Assessment of Outcomes}

There were 15 outcomes within the 10 studies for which E-S could be calculated [18,20,26,30,31,33,34,36-38] (Figure 2). Of these, 4 had a non-significant E-S [20,30,31,33]. The E-S ranged form 0.27 (95\%CI: -0.0 to $0.59)$ for attitudes outcome [20] to 1.32 (95\%CI: 1.11 to 1.53) for total test score [36] (Figure 2).

Within the outcomes groups, 2 of the total test score outcomes had a significant E-S $>0.79$. Five studies assessed skills, two assessed behavior and two assessed attitudes. All had a "small to moderate" E-S (range: 0.2 to 0.5 ). One of the two studies which assessed knowledge had E-S of 0.57 (95\%CI: 0.32 to 0.82 ) [20] defined as "moderate to large", while the other study had a "small to moderate" E$\mathrm{S}$ [30]. None of the knowledge, skills, attitudes and behavior outcomes had E-S > 0.79 (Figure 3).

We found that of the different types of intervention, the workshop was the most frequent intervention (35.3\%), followed by multifaceted intervention (29.6\%) (see Additional file 1 and Figure 2).

\section{Quality assessment}

We used an adaptation of the quality measure from Reed et al. [14]. We examined 13 criteria of study quality (see Additional file 2). On average, the studies met more than half of the quality criteria. Only two studies met the criteria "Are long term effects assessed?" $[38,42]$ and only one
Table I: Psychometric characteristics of educational instruments

\begin{tabular}{lc}
\hline \multicolumn{1}{c}{ Characteristics } & $\begin{array}{c}\text { Tested; } \mathrm{n}= \\
22 \mathrm{~N}(\%)\end{array}$ \\
\hline Validity & \\
OContent & $6(27.3)$ \\
ODiscriminative & $6(27.3)$ \\
OResponsive & $20(90.9)$ \\
Reliability & \\
OCronbach Alpha & $5(22.7)$ \\
OKappa & $2(0.09)$ \\
O Intra-class correlation & $3(13.6)$ \\
Instruments with $\geq 2$ types of validity and reliability test & $10(45.4)$
\end{tabular}

Categories are not mutually exclusive

study did not meet the criteria "Is validity of instruments reported?

\section{Discussion}

This review sought to identify those studies that examined the effectiveness of EBP education in improving knowledge, skills, behavior and attitudes in EBP in postgraduate

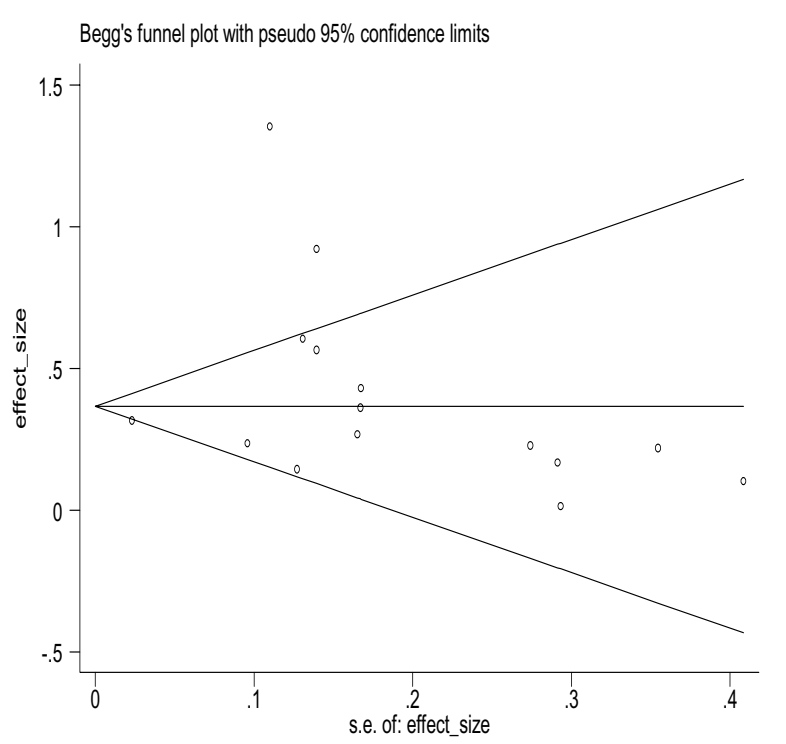

\section{Figure 2}

Funnel-plot of the effect size of size of randomized-controlled trials, non randomized-controlled trials and before-after studies. 


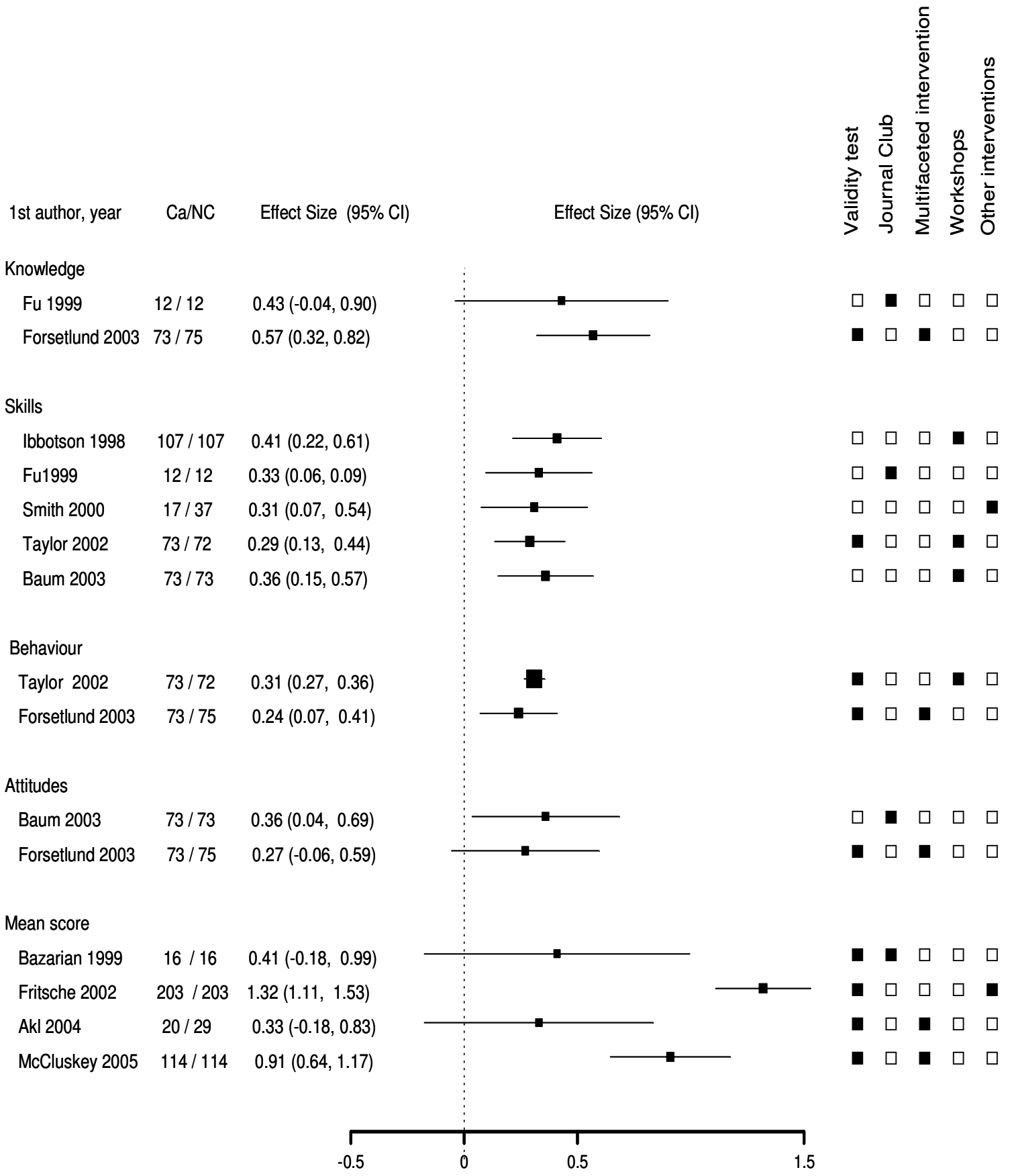

\section{Figure 3}

Forest Plot of the effect size (E-S) of randomized-controlled trials, non randomized-controlled trials and before-after studies. E-S corresponds to magnitude of an intervention effect. Boxes are the E-S estimates from each study. The horizontal bars are $95 \% \mathrm{Cl}$. The size of the box is proportional to the weight of the study. The studies are sorted by weight in the plot. The table on the right side of the graph indicates whether two or more types of validity were used and what kind of intervention was used: Journal Club or workshops, or multifaceted intervention, or other interventions. Yes; $\square$ No. 
health care. This is important from the medical education standpoint with intervention as a means of improving the quality of care provision. In our review we identified a small significant improvement in skills, knowledge, behavior and attitudes after EBP intervention. We identified a large improvement (E-S > 0.79) in EBP when measured as a total test score. Two of the four studies [36,38] included that had measured total test score had shown an E-S of up to 0.79 . Both studies had used a validation test with high reliability and validity in assessing knowledge and skill in all the usual domains of evidence based medicine by asking focused questions, by searching for good answers, by critiquing literature, and by applying the conclusions to practice[36,43].

However, the poor quality of these studies precludes conclusions being made on the E-S of improving knowledge, skills, attitudes or behavior following EBP education. Of the 21 studies, 7 were before-after studies and did not employ a non-intervention group for comparison. The majority of the studies had small sample size; median of 59 participants (range, 12-800). Many studies provide little detail on how the questionnaires were developed and validated, how the questionnaires were administrated and how long before the intervention. All the studies were conducted in North America, the United Kingdom, Australia, Germany and Hong Kong, and do not accurately reflect developing countries. Only two studies were designed to assess long-term effect on skills $[26,38]$ while the rest of the studies assessed short-term learning. The studies in this review were not able to distinguish whether the observed outcomes were the result of receiving the intervention or the desire of the health care professional to change. Integrating theories of behavior change into education programs is one of the keys for successful education development. Sustained learner behavior and change in attitude of individuals with high motivation to learn were more active in the education programs[44].

Our results are consistent with a previous systematic study [11] which found small changes in knowledge at the level of the resident but, in contrast, this improvement was high in undergraduate medical students. And another systematic review [10] showed that standalone teaching improved knowledge but not skills, attitudes or behavior. Finally, a systematic review of the effectiveness of critical appraisal skills in the training of clinicians showed an overall improvement of $68 \%$ in assessed outcomes following intervention, but only one study used a randomized controlled design and the methodological quality of the studies included was poor [13].

This review focused as well on examining which studies had used a validation instrument to assess the effectiveness of the intervention. Changes in health cares' knowl- edge and skills are relatively easy to detect with validation instruments, but changes in behavior and attitudes are more difficult to measure. Several authors have proposed assessment in the practice setting, or by conducting qualitative studies $[37,45]$. None of the studies reported health care outcomes and none of had documented any measure of ease-of-implementation, time required to administer the instrument, time required to score the instrument or the costs of administering and of scoring. Only 9 of the 19 instruments (47.4\%) revised 2 or more types of validity or reliability. Choice of measurement method is a crucial step in the evaluation of educational interventions because many evaluation methods are not sensitive enough to measure the effectiveness of the interventions, and which could lead to incorrect interpretation of results [14]. Also, the use of validated tests enable comparison of results to be made between different studies[14,46]. This is an important area for further research, and one in which healthcare research workers need to document the reliability and validity of existing measures, rather than to continue developing new instruments for each new project.

As with our present review, but with a smaller number of studies reviewed, only one other systematic review of EBP teaching had addressed the effectiveness of educational interventions and had included detailed analysis of the evaluation instrument [12]. Another systematic review assessed the available EBP teaching instrument methods but did not report on the effectiveness of EBP teaching [15]. The results of our systematic review confirm the findings of previous assessments indicating that few types of validity and of reliability evidence are contained in the instruments evaluating education in EBP.

There are several limitations in this current review. The eligibility of the studies in our systematic evaluation was limited to published reports. Our resources did not permit an extensive search of the literature outside of the stated databases. However, a study has shown that results of reviews incorporating non-catalogued literature do not differ substantially from those reviews that do contain them [47], and no significant publication bias was found in our analyses. One of the strengths of the present systematic review is the use of the effect-size; the goal being to obtain a standardized outcome measure which would enable comparisons to be made of the results from different studies.

The results of this review provide an outline of common themes for future research: (a) randomized controlled studies with appropriate study sample size and using validated tests are warranted in assessing the effectiveness of EBP training; (b) developing and trans-culturally adapted instruments with strong evidence of validity and reliability and whose evaluation domains correspond to assess- 
ing knowledge, skills, attitudes and behavior in EPB; (c) studies to examine the importance of personality traits and intention-to-change of health-care professionals; (d) studies to improve outcomes for patients by increasing physicians' knowledge, skills and attitudes towards EBP; (e) integration of theories of behavior-change into education programs and to measure the effect on clinical competence.

\section{Conclusion}

Randomized controlled trials, non-randomized controlled trials and before-after studies showed a small improvement in knowledge, skills, attitudes and behavior following EBP, together with a large improvement in knowledge and skills when measured as a total test score. However, the quality of the evidence precludes practical recommendations to be introduced in EBP education in postgraduate health-care professionals. More research into education in medicine is needed. Greater collaboration with organizations and individuals interested in preserving standards in academic medicine is required. Programs of training health-care professionals have responsibility for education and research. These programs must stimulate interest in EBP education and must evaluate these interventions. EBP education and other types of medical education interventions should be evaluated in a similar manner as that expected for interventions such as drug therapy or diagnostic studies.

\section{Competing interests}

The author(s) declare that they have no competing interests.

\section{Authors' contributions}

JMA and GFM were equally responsible for design, quality assessment, review of studies, and preparation of the manuscript.

\section{Additional material}

\section{Additional file 1}

Characteristics of studies assessing effectiveness of teaching critical appraisal skills. this table provided information about the assessing effectiveness of teaching critical appraisal skills.

Click here for file

[http://www.biomedcentral.com/content/supplementary/14726963-7-119-S1.doc]

\section{Additional file 2}

Quality criteria for evaluating studies. This table ass the quality criteria of studies included in the systematic review.

Click here for file

[http://www.biomedcentral.com/content/supplementary/14726963-7-119-S2.doc]

\section{Acknowledgements}

We thank the Foundation IDIAP Jordi Gol for financial help in the English language translation and editing of the manuscript.

\section{References}

I. Grol R, Grimshaw J: From best evidence to best practice: effective implementation of change in patients' care. Lancet 2003, 362: $1225-1230$

2. Brown LC, Johnson JA, Majumdar SR, Tsuyuki RT, McAlister FA: Evidence of suboptimal management of cardiovascular risk in patients with type 2 diabetes mellitus and symptomatic atherosclerosis. CMAJ 2004, I 1 I: I I89- I I 92.

3. McGlynn EA, Asch SM, Adams J, Keesey J, Hicks J, DeCristofaro A, Kerr EA: The quality of health care delivered to adults in the United States. N Engl J Med 2003, 348:2635-2645.

4. Leape LL, Weissman JS, Schneider EC, Piana RN, Gatsonis C, Epstein AM: Adherence to practice guidelines: the role of specialty society guidelines. Am Heart J 2003, 145: 19-26.

5. Avezum A, Cavalcanti AB, Sousa AG, Farsky PS, Knobel M: [Adjuvant therapy in acute myocardial infarction: evidence based recommendations]. Rev Assoc Med Bras 2000, 46:363-368.

6. Barzansky B, Etzel Sl: Educational programs in US medical schools, 2004-2005. JAMA 2005, 294:1068-1074.

7. Medicine I: Health Professions Education: A bridge to quality Edited by: Press NA. Washington DC; 2003.

8. Hatala R, Guyatt G: Evaluating the teaching of evidence-based medicine. JAMA 2002, 288: I I I0-III 2 .

9. Sackett DL, Rosenberg WM, Gray JA, Haynes RB, Richardson WS: Evidence based medicine: what it is and what it isn't. $B M$ 1996, 3 I 2:7I-72.

10. Coomarasamy A, Khan KS: What is the evidence that postgraduate teaching in evidence based medicine changes anything? A systematic review. BMJ 2004, 329:1017.

11. Norman GR, Shannon SI: Effectiveness of instruction in critical appraisal (evidence-based medicine) skills: a critical appraisal. CMAJ 1998, I58:177-18I.

12. Green ML: Graduate medical education training in clinical epidemiology, critical appraisal, and evidence-based medicine: a critical review of curricula. Acad Med 1999, 74:686-694.

13. Taylor S, Muncer S: Redressing the power and effect of significance. A new approach to an old problem: teaching statistics to nursing students. Nurse Educ Today 2000, 20:358-364.

14. Reed D, Price EG, Windish DM, Wright SM, Gozu A, Hsu EB, Beach $M C$, Kern D, Bass EB: Challenges in systematic reviews of educational intervention studies. Ann Intern Med 2005, 142: 1080-1089.

15. Shaneyfelt T, Baum KD, Bell D, Feldstein D, Houston TK, Kaatz S, Whelan C, Green M: Instruments for evaluating education in evidence-based practice: a systematic review. JAMA 2006, 296: III6-II27.

16. Rosenthal: Meta-analytic procedures for combining studies with multiple effect sizes. Psychological Bulletin 1986, 99:400-406.

17. J. DG: The Effect Size Generator. 2004 [http://www.swin.edu.aul victims].

18. Taylor RS, Reeves BC, Ewings PE, Taylor RJ: Critical appraisal skills training for health care professionals: a randomized controlled trial [ISRCTN46272378]. BMC Med Educ 2004, 4:30.

19. Cheng GY: Educational workshop improved informationseeking skills, knowledge, attitudes and the search outcome of hospital clinicians: a randomised controlled trial. Health Info Libr J 2003, 20 Suppl I:22-33.:22-33.

20. Forsetlund L, Bradley P, Forsen L, Nordheim L, Jamtvedt G, Bjorndal $A$ : Randomised controlled trial of a theoretically grounded tailored intervention to diffuse evidence-based public health practice [ISRCTN23257060]. BMC Med Educ 2003, 3:2.

21. Linzer M, Brown JT, Frazier LM, DeLong ER, Siegel WC: Impact of a medical journal club on house-staff reading habits, knowledge, and critical appraisal skills. A randomized control trial. JAMA 1988, 260:2537-254I.

22. Macrae HM, Regehr G, McKenzie M, Henteleff H, Taylor M, Barkun J, Fitzgerald GW, Hill A, Richard C, Webber EM, McLeod RS: Teaching practicing surgeons critical appraisal skills with an Internet-based journal club: A randomized, controlled trial. Surgery 2004, 136:641-646. 
23. Schilling K, Wiecha J, Polineni D, Khalil S: An interactive webbased curriculum on evidence-based medicine: design and effectiveness. Fam Med 2006, 38: I26-132.

24. Stevermer JJ, Chambliss ML, Hoekzema GS: Distilling the literature: a randomized, controlled trial testing an intervention to improve selection of medical articles for reading. Acad Med 1999, 74:70-72.

25. Cabell CH, Schardt C, Sanders L, Corey GR, Keitz SA: Resident utilization of information technology. J Gen Intern Med 200I, 1 6:838-844

26. Smith CA, Ganschow PS, Reilly BM, Evans AT, McNutt RA, Osei A, Saquib M, Surabhi S, Yadav S: Teaching residents evidence-based medicine skills: a controlled trial of effectiveness and assessment of durability. J Gen Intern Med 2000, I 5:710-7I5.

27. Villanueva EV, Burrows EA, Fennessy PA, Rajendran M, Anderson JN Improving question formulation for use in evidence appraisal in a tertiary care setting: a randomised controlled trial [ISRCTN66375463]. BMC Med Inform Decis Mak 200 I, I:4.

28. Haynes RB, Johnston ME, McKibbon KA, Walker CJ, Willan AR: A program to enhance clinical use of MEDLINE. A randomized controlled trial. Online J Curr Clin Trials 1993, Doc No 56:4005.

29. Green ML, Ellis PJ: Impact of an evidence-based medicine curriculum based on adult learning theory. J Gen Intern Med 1997, I 2:742-750

30. FU: Is a journal club effective for teaching critical appraisal skills? Academic Psychiatry 1999, 23:205-209.

31. Bazarian JJ, Davis CO, Spillane LL, Blumstein H, Schneider SM: Teaching emergency medicine residents evidence-based critical appraisal skills: a controlled trial. Ann Emerg Med 1999, 34:148-154.

32. Ross R, Verdieck A: Introducing an evidence-based medicine curriculum into a family practice residency--is it effective? Acad Med 2003, 78:4I2-4I7.

33. Akl EA, Izuchukwu IS, El Dika S, Fritsche L, Kunz R, Schunemann HI: Integrating an evidence-based medicine rotation into an internal medicine residency program. Acad Med 2004, 79:897-904.

34. Ibbotson T, Grimshaw J, Grant A: Evaluation of a programme of workshops for promoting the teaching of critical appraisal skills. Med Educ 1998, 32:486-491.

35. Kellum JA, Rieker JP, Power M, Powner DJ: Teaching critical appraisal during critical care fellowship training: a foundation for evidence-based critical care medicine. Crit Care Med 2000, 28:3067-3070.

36. Fritsche L, Greenhalgh T, Falck-Ytter Y, Neumayer HH, Kunz R: Do short courses in evidence based medicine improve knowledge and skills? Validation of Berlin questionnaire and before and after study of courses in evidence based medicine. $B M$ 2002, 325: |338-|34|.

37. Baum, D K: The impact of an Evidence-Based Medicine workshop on residents' attitudes towards and self-reported ability in evidence-based practice. 2003, 8: [http://www.med-edonline.org/res00053.htm]

38. McCluskey A, Lovarini M: Providing education on evidencebased practice improved knowledge but did not change behaviour: a before and after study. BMC Med Educ 2005, 5:40.

39. Straus SE, Ball C, Balcombe N, Sheldon J, McAlister FA: Teaching evidence-based medicine skills can change practice in a community hospital. J Gen Intern Med 2005, 20:340-343.

40. Dinkevich E, Markinson A, Ahsan S, Lawrence B: Effect of a brief intervention on evidence-based medicine skills of pediatric residents. BMC Med Educ 2006, 6:I.

41. Lucas BP, Evans AT, Reilly BM, Khodakov YV, Perumal K, Rohr LG, Akamah JA, Alausa TM, Smith CA, Smith JP: The impact of evidence on physicians' inpatient treatment decisions. I Gen Intern Med 2004, 19:402-409.

42. Smith AD, South PK, Levander OA: Effect of gold(I) compounds on the virulence of an amyocarditic strain of coxsackievirus B3. Biol Trace Elem Res 2001, 84:67-80.

43. Ramos KD, Schafer S, Tracz SM: Validation of the Fresno test of competence in evidence based medicine. BMJ 2003, 326:319-32I.

44. Kinzie MB: Instructional design strategies for health behavior change. Patient Educ Couns 2005, 56:3-15.

45. Straus SE, Green ML, Bell DS, Badgett R, Davis D, Gerrity M, Ortiz E, Shaneyfelt TM, Whelan C, Mangrulkar R: Evaluating the teaching of evidence based medicine: conceptual framework. $B M$ 2004, 329: 1029-1032.

46. Boon H, Stewart M: Patient-physician communication assessment instruments: 1986 to 1996 in review. Patient Educ Couns 1998, 35:161-I76.

47. Egger M, Juni P, Bartlett C, Holenstein F, Sterne J: How important are comprehensive literature searches and the assessment of trial quality in systematic reviews? Empirical study. Health Technol Assess 2003, 7:1-76.

\section{Pre-publication history}

The pre-publication history for this paper can be accessed here:

http://www.biomedcentral.com/1472-6963/7/119/pre pub

Publish with BioMed Central and every scientist can read your work free of charge

"BioMed Central will be the most significant development for disseminating the results of biomedical research in our lifetime. "

Sir Paul Nurse, Cancer Research UK

Your research papers will be:

- available free of charge to the entire biomedical community

- peer reviewed and published immediately upon acceptance

- cited in PubMed and archived on PubMed Central

- yours - you keep the copyright
BioMedcentral 